\title{
X-RAY ANALYSIS OF A QUARTZ FABRIC FROM THE SAMBAGAWA CRYSTALLINE SCHIST, JAPAN
}

\author{
IKUO HARA and P. PAULITSCH \\ Institute of Geology and Mineralogy, Faculty of Science, \\ Hiroshima University, Hiroshima, 730, Japan; and Mineralogisches Institut der Technischen \\ Hochschule Darmstadt, 61 Darmstadt, Germany
}

(Received February 29, 1972, in final form June 8, 1972)

\begin{abstract}
An X-ray fabric analysis of quartz grains from the Sambagawa crystalline schist, Japan, whose c-axis fabric (optically measured) was regarded as corresponding to an ultimate steady-state pattern of preferred orientation of c-axes developed by the approximately non-rotational two-dimensional strain under the Sambagawa metamorphic conditions, has been made by a texture goniometer for reflection. It has been clarified that [0001] and [10I1] directions are preferably oriented in the plane of the longest and shortest principal axes of the strain ellipsoid of mean strain of the system concerned and at the angles of ca. $35^{\circ}$ and ca. $17^{\circ}$ to the shortest principal axis respectively.
\end{abstract}

\section{INTRODUCTION}

The deformation history of the Sambagawa metamorphic terrain, Japan, is very complex, showing several phases of deformation. The authors have attempted to understand the nature of large paracrystalline deformation of quartz under the Sambagawa metamorphic conditions on the basis of analysis of quartz fabrics at the hinge zones of the orthorhombic buckle folds of quartz-rich layers, which formed during the last phase of the folding history immediately before kinking and fracturing occurred. Two distinct types of large paracrystalline deformation of quartz have been recognized, i.e., (1) large deformation of quartz grains unaccompanied with fragmentation of them (C-type of deformation, ${ }^{1}$ ) and (2) deformation of quartz grains accompanied with formation of recrystallized secondary grains (F-type of deformation, ${ }^{2,3}$ ). It has been concluded that, for quartz grains showing the C-type of deformation, ultimate steady-state pattern of c-axis fabric developed under the strain condition, which approximates to a nonrotational two-dimensional strain, is characterized by high concentration of c-axis in two positions which are placed in the plane of the longest and shortest principal axes of the strain ellipsoid at the angle of $30^{\circ}-40^{\circ}$ to the shortest principal axis. This pattern of c-axis fabric has been observed in the schists of various metamorphic grades from epidote- amphibolite facies to the intermediate between the blueschist facies and the greenschist facies. ${ }^{1}$

The purpose of this paper is an X-ray analysis of the lattice fabric of quartz grains showing the C-type of deformation whose c-axis fabric is referred to the above-mentioned ultimate steady-state pattern of preferred orientation of c-axes, clarifying preferred orientation of other crystallographic directions with reference to the principal axes of the strain ellipsoid of mean strain in the system concerned.

\section{X-RAY ANALYSIS}

\section{Selection of Specimen}

The c-axis fabrics of quartz grains showing the C-type of deformation, whose pattern can be regarded as corresponding to the ultimate steadystate pattern of preferred orientation of c-axes developed under the approximately non-rotational two-dimensional strain, were found at the innermost hinges of some buckle folds of quartzrich layers collected from some small outcrops (the Kawaguchi, the Saijyo and the Kotsu outcrops ${ }^{1}$ ) in the Sambagawa metamorphic terrain. Because the pattern of the c-axis fabric at the hinges of those folds changes gradually but distinctly with positional change from the convex side to the concave side, generally, quartz grains showing the stable 

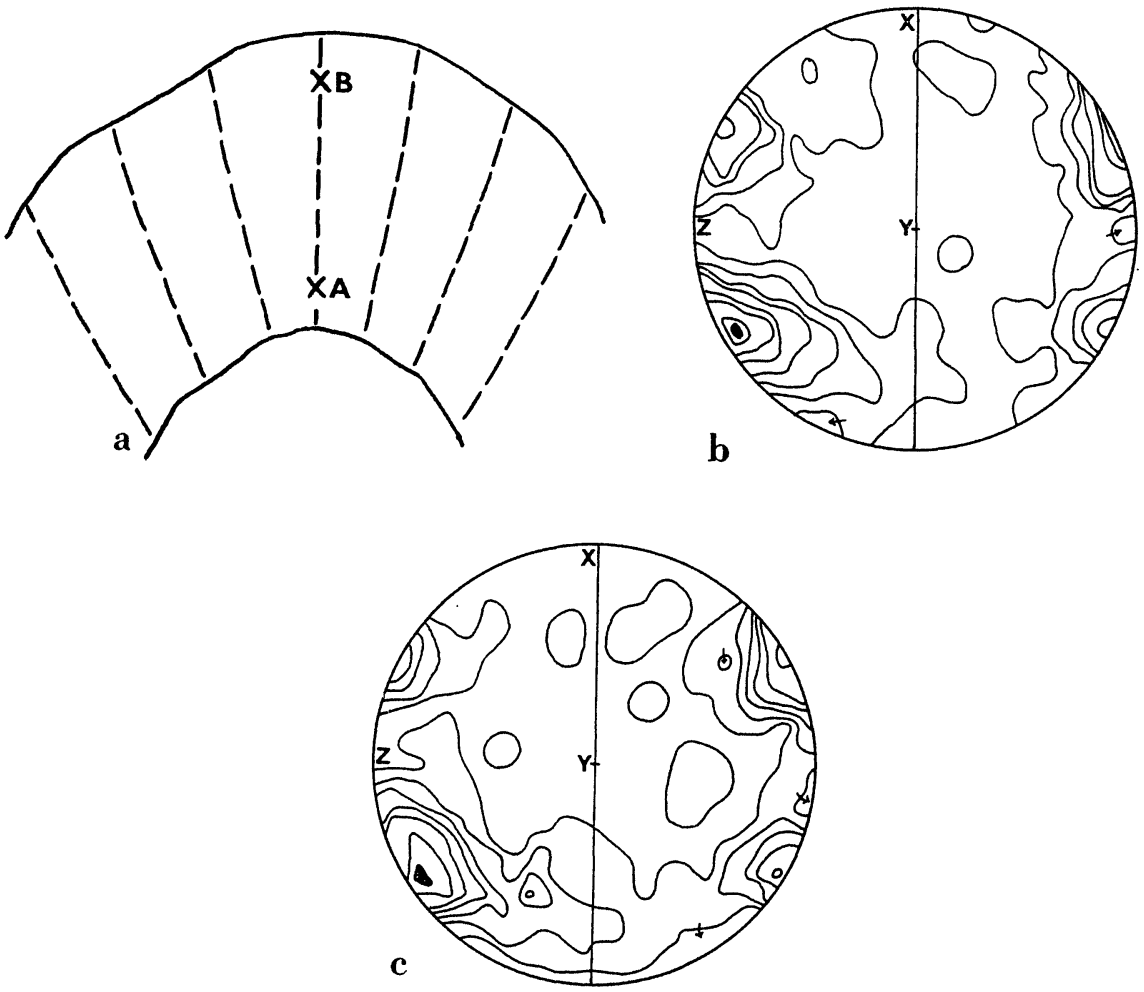

FIGURE 1 Fabric data optically measured. (a) The trajectories of direction of preferred dimensional orientation of quartz through the fold. A and B: positions for measurement of c-axis fabric. (b) c-axis fabric of 150 quartz grains at position A. Contours: $15-13-10-6-4-3-2-0.6 \%$ per $1 \%$ area. (c) c-axis fabric of 150 quartz grains at position B. Contours: $13-10-6-4-3-2-0.6 \%$ per $1 \%$ area. In the diagrams $b$ and $c, X, Y$ and $Z$ are the principal axes of strain, according to the ellipsoidal grain shape, where $\mathrm{X}>\mathrm{Y}>\mathrm{Z}$. $\mathrm{Y}$ is parallel to the fold axis and $\mathrm{Z}$ is normal to the axial surface. Arrows show minima.

pattern of c-axis fabric have been found only within a very small domain in the innermost part of the hinge.

The X-ray measurement of preferred orientation of quartz lattices with a texture goniometer using the technique of Schulz ${ }^{4}$ for reflection can be made with success only when the quartz lattice fabric is homogeneous within the portion of a specimen examined, and in which more than $10^{4}$ grains are always irradiated by X-ray (cf., 5, 6) and those grains do not show great variation in size (cf. ref.7). From this point of view, the quartz fabrics at the hinges of many buckle folds in quartz-rich layers from the Kawaguchi, Saijyo and Kotsu outcrops do not appear to be appropriate for determination of preferred orientation with the texture goniometer $\dagger$ used by the authors, ${ }^{7-9}$ because the domain showing the stable fabric is too small.

$\uparrow$ Manufactured by Siemens Comp.

\section{Optical Measurement}

For one of the orthorhombic folds of quartz-rich layers from the Kotsu outcrop in which the strain in the fold can be commonly regarded as twodimensional strain, ${ }^{1}$ the c-axis fabric was approximately homogeneous throughout the whole part of hinge, in which the thickness of the layer is about $12 \mathrm{~mm}$. Figures $1 \mathrm{~b}$ and $\mathrm{c}$ illustrate the $\mathrm{c}$-axis fabric at the innermost hinge (position $A$ and Figure 1a) and the outermost hinge (position $\mathrm{B}$ ) respectively, which has been measured on the plane normal to the fold axis. Though the pattern of those figures is of the "crossed-girdle" type, the position of maxima is essentially the same as that for the stable c-axis fabric of Hara. ${ }^{1}$ Quartz grains in this specimen are uniformly small in size, showing the average value of $0.045 \mathrm{~mm}$. The X-ray examination of the quartz fabric in a slab $3 \mathrm{~mm}$ thick cut from this specimen along the axial surface appears to give us adequate 
data regarding the preferred orientation. The results of an X-ray analysis of this specimen will be described in the following section.

\section{Results of X-ray Analysis}

In the Schulz reflection method there is a falling off of intensity, due to some causes not related to the nature of preferred lattice orientation in the specimen, with increase of the angle $\phi$ between the normal to the specimen and the plane of the incident and diffracted beams (e.g., refs. 4, 10, 11). Baker et $a l .{ }^{11}$ found that there is a marked dependence of intensity decrease on $2 \theta$ ( $\theta$ is the Bragg angle); that is, for reflections of higher $2 \theta$ the falling off of intensity begins at higher $\phi$. For example, for $\mathrm{Cu} \mathrm{K} \alpha$ radiation on planes (1010) and (1011) of quartz if begins at angles smaller than $35^{\circ}$, while for the plane $(11 \overline{2} 0)$ it begins at about $50^{\circ}$ (see Figure 3 in ref. 11). Generally, the dimensions of the irradiated portion increase with increase of $\phi$. But the change of the dimensions of irradiated portion tends to be smaller until high angles of $\phi$ when reflections of higher $2 \theta$ are used (see Figure 15 in ref. 7). Thus, in order to determine preferred lattice orientation of quartz in the present specimen in which the lattice orientation appears to be homogeneous only within a limited domain, intensities were measured for the planes $(11 \overline{2} 0)$, $(20 \overline{2} 0)$ and $(11 \overline{2} 2)$ which have high $2 \theta$ values ( $\mathrm{Cu} \mathrm{K} \alpha$ radiation) of $36.5^{\circ}, 42.4^{\circ}$ and $50.1^{\circ}$ respectively. Nickel-filtered $\mathrm{Cu} \mathrm{K} \alpha$ radiation was used at $35 \mathrm{kV}$ and $20 \mathrm{~mA}$.

Figures $2 a, b$ and $c$ illustrate orientations of planes $(11 \overline{2} 0),(20 \overline{2} 0)$ and $(11 \overline{2} 2)$ respectively.

The X-ray fabrics appear to be in good agreement with each other and also with the c-axis fabric (Figures $1 \mathrm{~b}$ and c) optically measured. Namely, those fabric data indicate that the pattern of preferred orientation of quartz in the present specimen will be drawn as schematically shown in Figure 3. The figure shows that the poles of planes

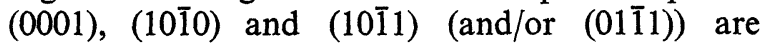
preferably oriented in the plane of the longest and shortest principal axes of the strain in the system
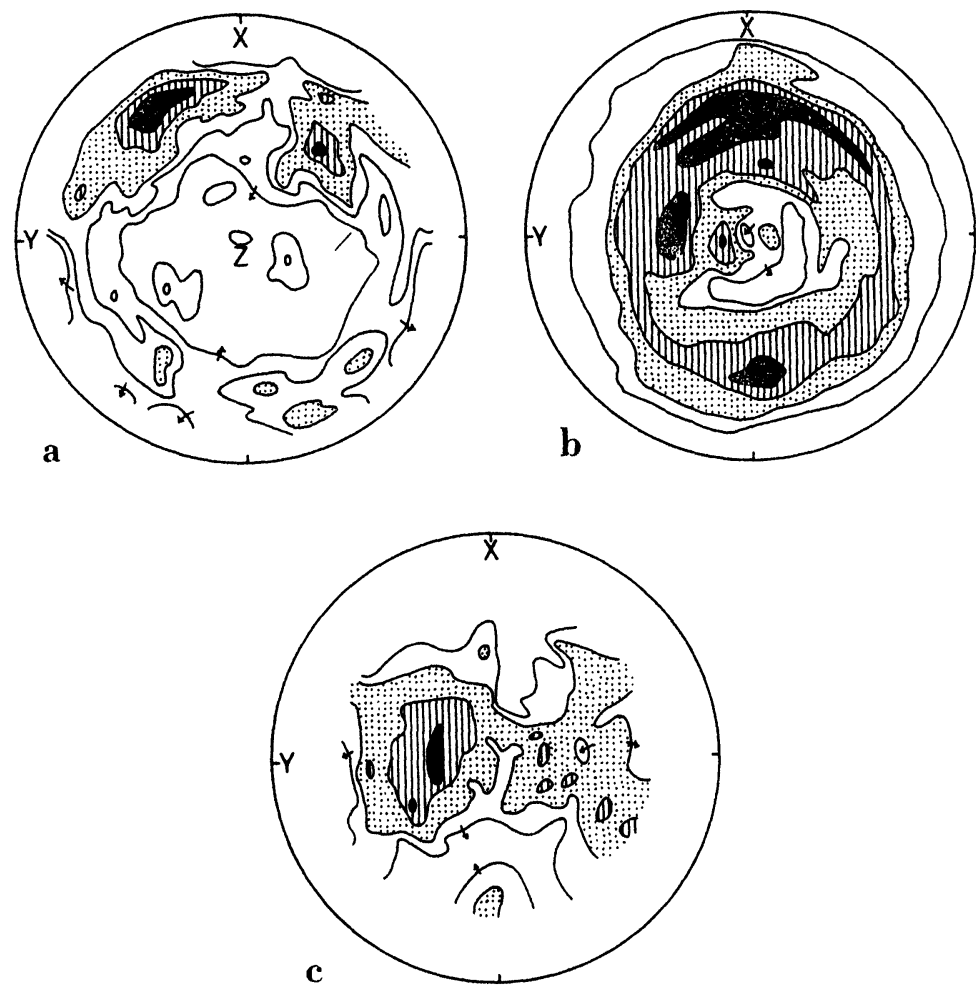

FIGURE 2 X-ray fabric data. (a) Orientation diagram for the plane (1120). Contours $0.38-0.28-0.18-0.13-$ $0.08 \times 10^{3} \mathrm{Imp} / \mathrm{min}$. (b) Orientation diagram for plane $(20 \overline{2} 0)$. Contours $0.36-0.31-0.26-0.21 \times 10^{3} \mathrm{Imp} / \mathrm{min}$. (c) Orientation diagram for plane (1122). Contours: $1.2-0.9-0.7-0.6 \times 10^{3} \mathrm{Imp} / \mathrm{min}$. In the diagrams, $X, Y$ and $\mathbf{Z}$ are the principal axes of strain. 
concerned, and that [0001) and (10i11] poles are placed at the angles of ca. $35^{\circ}$ and ca. $17^{\circ}$ to the shortest principal axis respectively. The preferred lattice orientation of quartz shown in Figure 3 will be regarded as corresponding to the stable lattice fabric developed by the approximately nonrotational two dimensional strain under the Sambagawa metamorphic conditions.

The fabric property of Figure 3 appears to be approximately consistent with that of the rmaximum (1011) fabric of Green et al., ${ }^{12}$ with reference to the nature of preferred orientation of [0001] and [1011] directions to the longest and shortest principal strain axes, though it will be difficult to claim a close correlation of the natural and experimental results because of the difference in the physical conditions between the former and the latter. Green et $a l^{12}$ have further shown that in the r-maximum fabric there is a marked difference in preferred orientation of the positive (1011) and negative (0111) unit rhombohedran, i.e., the preferred orientation of the poles to the positive unit rhombohedron is parallel to the maximum compression axis, using the method of Baker et al..$^{11}$ Tullis $^{13}$ has shown that such difference in preferred orientation of the positive and negative unit rhombohedra is due to mechanical Dauphiné twinning. In the present case however we have not tried to distinguish between the positive and negative unit rhombohedra. There is a great possibility that also in the present specimen the poles to the positive unit rhombohedran are preferably oriented nearly parallel to the shortest principal strain axis, from the data and considerations of Tullis $^{13}$ and Baker and Wenk ${ }^{14}$, showing that mechanical Dauphiné twinning occurs readily under various physical conditions.

\section{ACKNOWLEDGMENTS}

The first author (Hara) has benefited greatly from the continuous encouragement and interesting discussion provided by Prof G. Kojima of the Hiroshima University, Japan. The authors wish to thank Mr. Dietrich for his kind assistance to the preparation. The study of the first author in Mineralogisches Institut der Technischen Hochschule Darmstadt has been supported by Alexander von Humboldt-Stiftung, Germany.

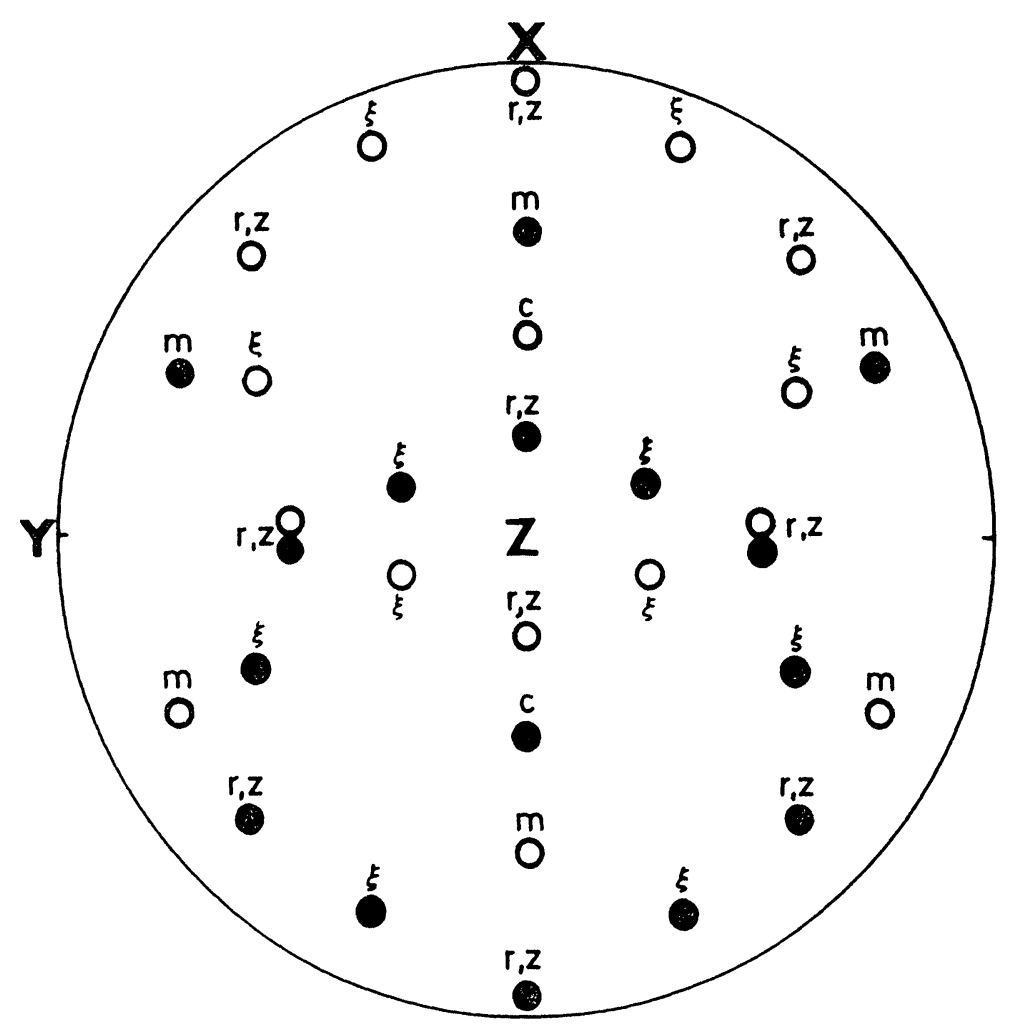

FIGURE 3. Schematic diagram showing preferred orientation of [0001]-, [1010]-, [1011]- and [1122]-directions (c, $\mathrm{m}, \mathrm{rZ}$ and $\xi)$ of quartz with reference to the principal axes of strain $(\mathrm{X}, \mathrm{Y}$ and $\mathrm{Z})$. 


\section{REFERENCES}

1. I. Hara, Geol. Rundschau 60, 3 (1971).

2. I. Hara and P. Paulitsch, N. Jb. Miner. Abh. 115, 1, 31-53 (1971).

3. I. Hara and P. Paulitsch, Fortschr. Miner. 48, 2, 268-270 (1971).

4. L. G. Schulz, J. appl. Phys. 20, 1030 (1949).

5. W. P. Chernock, M. H. Mueller, H. R. Fish, and P. A. Beck, Rev. Sci. Instr. 24, 925 (1953).

6. F. Haeßner, Metall 12, 89, 1094 (1958).

7. K. v. Gehlen, Beitr. Miner. Petrogr. 7, 340 (1960).
8. H. Neff, Z. Metallkunde 47, 646 (1956).

9. H. Neff and P. Paulitsch, Naturwiss. 46, 490 (1959).

10. H. Hu and P. A. Beck, Trans. AIME. 188, 1214 (1950).

11. D. W. Baker, H.-R. Wenk, and J. M. Christie, J. Geol. 77, 144 (1969).

12. H. W. Green, II, D. T. Griggs, and J. M. Christie Festschrift BRUNO SANDER, (Springer, Heidelberg, 1970), pp. 272-335.

13. J. Tullis, Science 168, 1342 (1970).

14. D. W. Baker and H.-R. Wenk, Trans. Amer. Geophys. Union 50, 323 (1969). 